\title{
A Comparative Study of Leptin, Oxidant/Antioxidant Status and Some Trace Elements in Women of Healthy Control and Unexplained Infertility in Basrah-Iraq
}

\author{
Adnan Jassim Mohammed Al-Fartosy*, Nadhum Abdulnabi Awad, Rsha Abdulradha Mahmood \\ Department of Chemistry, College of Science, University of Basra, Basra, Iraq \\ *Corresponding author. E-mail: adnan.jassim@uobasrah.edu.iq
}

Received date: Jul 15, 2019; Revised date: Sep 5, 2019; Accepted date: Sep 13, 2019

\section{Abstract}

B ACKGROUND: To date, there is no study regarding women with unexplained infertility in the province of Basrah, Iraq. This study was conducted to compare the level of leptin, oxidant/antioxidant status, and some trace element levels in women of healthy control and unexplained infertility.

METHODS: From total 96 women subjects, 32 subjects had primary unexplained infertility, 31 had secondary unexplained infertility, while 33 fertile women were taken as controls. The body mass index (BMI) of subjects was calculated with standard procedures. The level of fasting serum leptin, luteinizing hormone (LH), follicle stimulating hormone (FSH), prolactin (PRL), thyroid-stimulating hormone (TSH), 4-hydroxynonenal (4-HNE), lipid hydroperoxide (LOOH), glutathione (GSH), superoxide dismutase (SOD), catalase (CAT) and the total antioxidant capacity (TAC) were determined by enzyme-linked immunosorbent assay (ELISA) methods. Magnesium (Mg) and zinc $(\mathrm{Zn})$ were measured by flame, copper $(\mathrm{Cu})$ by

\section{Introduction}

Unexplained infertility may be defined as a diagnosis of exclusion, since more than $25 \%$ of patients who visit reproductive and infertility medicine clinics are diagnosed with unexplained infertility. Normally, the diagnosis of unexplained infertility is made after the laboratory investigations show normal levels of semen parameters, flameless atomic absorption spectrometry, while Selenium (Se) in whole blood was determined using hydride generation method.

RESULTS: Non-significant changes $(p>0.05)$ were seen in the level of BMI, leptin, TSH, FSH, LH and LH/FSH ratio. Level of 4-HNE, $\mathrm{LOOH}$ and $\mathrm{Cu}$ were significantly increased ( $p<0.01)$, while level of GSH, SOD, CAT, TAC, $\mathrm{Se}, \mathrm{Zn}$ and $\mathrm{Mg}$ were significantly decreased $(p<0.01)$ in primary and secondary type of unexplained infertility, compared to control.

CONCLUSION: Serum leptin hormone is significantly associated with BMI and physical activity in both groups. The significant difference in oxidant/antioxidants status between unexplained infertile and fertile women may suggests a possible additional role of oxidative stress mechanisms in pathophysiology of unexplained infertility.

KEYWORDS: unexplained infertility, leptin, oxidative stress, antioxidants, trace elements

Indones Biomed J. 2019; 11(3): 327-37 ovulatory levels of serum progesterone hormone in the mid-luteal phase, tubal patency and a also normal cavity of uterine. Although, several possibilities have been proposed, but the etiology of this type of infertility remains unknown. In some couples with unexplained infertility, there are some subtle changes reported in the follicle development, ovulation and the luteal phase, as well as in the sperm concentration and motility at the lower end of the normal range. $(1,2)$ 
However, many scientific evidence from clinical studies proved that an imbalance between reactive oxygen species (ROS) and antioxidant actions could result in oxidative stress, which plays a major role in the etiology and increased complications of adverse reproductive events in both women and men.(3) These studies suggest that significantly increased free radicals may lead to deleterious physiological functions in female reproduction, such as in the process of oocyte maturation, ovarian steroidogenesis, ovulation, implantation, and the formation of fluid filled cavity, blastocyst, luteolysis, as well as the luteal maintenance in pregnancy. Furthermore, free radicals may also acts as mediators of various signaling pathways, thus elevated free radicals levels may leads to the imbalance intracellular redox homeostasis, which can be neutralized by antioxidants, as well as any imbalance in the ratio of oxidants/antioxidants which can cause oxidative stress.(4) On the other hand, nowadays oxidative stress may have an harmful roles in all pathologies of female reproductive tract like unexplained infertility, polycystic ovarian syndrome, endometriosis, tubal factor infertility, fibroids, recurrent pregnancy loss and spontaneous abortions. Researchers also demonstrated that oxidative stress are involved in more than one hundred diseases known today, such as hypo- and/or hyper-thyroidisms, fetal teratogenicity, intrauterine growth retardation, hydatiform mole, oligospermia, asthenospermia, azospermia, and this may result in immense burden on maternal, fetal morbidity and mortality.(5) Moreover, increased free radicals may causes depletion of adenosine triphosphate (ATP) levels, lipid peroxidation, and mutation of nucleic acids, proteins denature and damage of other cellular materials.

The adipokine, leptin, is represented as an important hormonal factor which affects females ovulation and the ovary functions through both paracrine and endocrine actions.(6) It also plays a vital role as a neuroendocrine mediator for different systems in the body, like the reproductive systems as well as a major regulator for food intake, energy homeostasis and body weight regulation.(7) This neuropeptide has molecular weight of $16 \mathrm{kDa}$ and the primary structure consists of 167 amino acids coded by the $o b$ gene in mice which is responsible for obesity, and its equivalent gene in humans is called $L E P$ gene. This hormone is able to reduce the oxidation of glucose and synthesis of fat, then increases fat intake.(8) It is mainly secreted from white adipose tissues (adipocytes) and some minor sources from other cells, such as hypothalamus, pituitary gland, placental syncytiotrophoblast cells, skeletal muscle, bone marrow, epithelial gastric cells, breast epithelium and ovarian follicles.(9) Leptin has a regulatory effects on reproduction may depend on a complex set of functions which results from the widespread distribution of leptin receptors along the hypothalamic-pituitary-gonadal axis, thus directly affect on target organs such as the placenta and the mammary glands as well as have major physiological effects on puberty, menstrual cycle, pregnancy, lactation and early embryo development. It has another peripheral function through regulation of insulin secretion and action, reproductive functions, angiogenesis, immune responses and synthesis of cortisol from adrenal cortex, it also involved in the homeostasis of glucose metabolism. Leptin has central effects for the regulation of appetite, temperature, weight and metabolism in the hypothalamus.(7) Scientific studied indicated that leptin is also produced by the ovary, and the estradiol hormone has a stimulatory effect on its production. It found that leptin in low concentrations has stimulatory effects, and has inhibitory effects on gonadotropins in high concentrations. Due to its association with the ovary the production of estradiol and progesterone, leptin may inhibits and prevents the progression of mature follicles.(6-7)

The available data on the pathophysiology role of leptin in infertility are controversial, especially for endometriosis-related infertility. A recent scientific study showed that levels of leptin was shown to be increased in serum and peritoneal fluid of women with endometriosis compared to the healthy control group, although the serum leptin concentration was similar in idiopathic infertile, infertile and fertile endometriotic patients.(10) Therefore, further work must be carried out to find and described the relationship of serum leptin and unexplained infertility. To date, in the province of Basrah (southern of Iraq), there has been no study investigating women with unexplained infertility. Hence, in the present study, an attempt was made to compare the level of leptin, oxidant/antioxidant status and some trace elements level in women of healthy control and unexplained infertility in Basrah-Iraq.

\section{Methods}

\section{Subjects}

This study was an interventional prospective randomized controlled clinical trial. Samples were collected from an infertility center at Basra Hospital for Obstetrics and Children in Basrah, Iraq during October 2018 to July 2019. For addition, some samples were also obtained from a private clinics run by consultant professor Dr. Abdulkareem Hussain Sabar and assistant professor Dr. Nateek 
Dicran Caspar in Obstetrics and Infertility Medicine Centre. As much as 130 women subjects were participated in the present study. Final 63 patients and 33 healthy controls were followed up for 8 months, utill end of the study. Meanwhile, the other 34 subjects (20 patients and 14 healthy controls) were dropped out from the study. The patients were already diagnosed as unexplained infertile patients according to the criteria from American College of Obstetricians and Gynecologists.(11) From 96 women that were screened for inclusion, 32 were with primary unexplained infertility (couple who had no previous pregnancies for at least one year after marriage) and 31 had secondary unexplained infertility (couple who have conceived previously, although the pregnancy may not have been successful for example, miscarriage, and ectopic pregnancy), while 33 fertile women visiting the hospital with a genital prolapsed and history of at least one childbirth were taken as controls. The sample populations were married women who live together with her husband and had not used any contraceptive method for a period of one year, but still had no children.

The study received an ethical approval from Basrah University (No. 7/54/4509), and an informed consents were obtained from each participant after detail explanation of the procedures. The informed consent and ethical guidelines were based on the deceleration of Helsinki for year 2000.

\section{Inclusion and Exclusion Criteria}

The inclusion criteria was women diagnosed to have unexplained infertility, including semen analysis, assessment of ovulation and tubal patency fail, to detect any gross abnormality. The subjects should had not conceived for one year of unprotected sexual intercourse, regular menstruation with the length of the cycle between 21-35 days, ovulation confirmed by appropriately timed mid-luteal progesterone (3-10 ng/mL), day 3 follicle stimulating hormone (FSH) level less than $10 \mu \mathrm{U} / \mathrm{mL}$ and bilateral tubal patency (demonstrated by laparoscopy or hystrosalpingography).

Meanwhile the exclusion criteria were patients aged less than 18 years old or more than 45 years old, infertile women with male factor infertility, infertile semen analysis, day 3 FSH more than $10 \mu \mathrm{U} / \mathrm{mL}$, medical disorders (such as polycystic ovary (PCO), hypo- and hyper-thyroidism, diabetes mellitus, hypertension, heart disease, malignancy, liver and renal diseases, pelvic pathology, or uterine fibroids). Subjects with previous history or planning for in vitro fertilisation (IVF), and not receiving drugs inducing ovulation in last six months, history of smoking to be identified, and any other diseases, which might have influenced our results, or an associated condition which can alter the level of free radicals such as antioxidant therapy were excluded from the study.

\section{Samples Preparation}

All blood samples were obtained in the morning between 09:00 and 10:00 hours after a 12 hours fasting and a 30 minutes of rest in the supine position. Blood was collected at 2-3 days of menstrual cycle, disposable plastic syringes and needles were used for blood collection. Ten $\mathrm{mL}$ of venous fasting blood samples were collected from patients and healthy volunteers by vein puncture then divided into two parts, the first $1 \mathrm{~mL}$ was added into ethylenediaminetetraacetic acid (EDTA) containing polypropylene tubes and shacked gently to be used for the measurement of the concentration of Selenium (Se). The remaining sample was transferred to plain tube (without anticoagulant) which allowed clotting in a clean plain tube for 30 minutes at room temperature. After the blood had clotted, it was placed in a centrifuge and spun at $402 \mathrm{x}$ g for 10 minutes to obtain the serum. The obtained serum immediately used in the detection of parameters in this study, and others were stored in deep freezing at $\left(-20^{\circ} \mathrm{C}\right)$ until used.

\section{Methods of Biochemical Estimation}

The body mass index (BMI) of subjects was calculated as the following formula: BMI $\left(\mathrm{kg} / \mathrm{m}^{2}\right)=$ weight $(\mathrm{kg}) /$ height $\left(\mathrm{m}^{2}\right)$. All the blood samples were analyzed for biochemical parameters by standard procedures. Serum leptin level was determined using the Human Leptin ELISA Kit (Catalogue No. E-EL-H0113, Ealbscience, Texas, USA), serum luteinizing hormone (LH) was estimated by $\mathrm{LH}$ Kit (Catalogue No. REF-53010, Human Gesellschaft for Biochemical and Diagnostic mbH, Germany), FSH was estimated by FSH Kit (Catalogue No.REF-53020, Human Gesellschaft for Biochemical and Diagnostic $\mathrm{mbH}$ ), prolactin (PRL) was estimated by PRL Kit (Catalogue No. REF53030, Human Gesellschaft for Biochemical and Diagnostic $\mathrm{mbH}$ ), thyroid-stimulating hormone (TSH) was estimated by TSH Kit (Catalogue No. REF-54030, Human Gesellschaft for Biochemical and Diagnostic mbH), 4-Hydroxynonenal (4-HNE) was estimated by 4-HNE Kit (Catalogue No. E-EL-0128, Ealbscience), lipid hydroperoxide (LOOH) was estimated by LOOH Kit (Catalogue No. E-BC-K176, Ealbscience), serum glutathione (GSH) was estimated by GSH Kit (Catalogue No. E-BC-K098, Ealbscience), superoxide dismutase (SOD) was estimated by SOD Kit (Catalogue No. E-BC-K022, Ealbscience), catalase (CAT), was estimated by CAT Kit (Catalogue No. E-BC-K031, Ealbscience), and total antioxidant capacity (TAC) 
was estimated by direct colorimetric method TAC Kit (Catalogue No. E-BC-K219, Ealbscience). Meanwhile the concentration of serum magnesium $(\mathrm{Mg})$ and zinc $(\mathrm{Zn})$ were measured by GBC 933 Plus flame atomic absorption spectrometry (AAS) (GBC, Braeside, Australia), serum copper $(\mathrm{Cu})$ was measured by 1TAA500-PG flameless AAS (PG Insturments, Leicestershire, England) (12), and the concentration of selenium (Se) in whole blood was determined using hydride generation method AAS (13).

\section{Statistical Analysis}

Statistical analysis was performed using SPSS software version 21 (IBM Corporation, New York, USA). The results were expressed as mean \pm standard deviation (SD). The $p<0.05$ was considered to be statistically significant and $p<0.01$ was considered to be highly significant.

\section{Results}

Ninety-six subjects were included in this study. From total 63 unexplained infertility subjects, 32 subjects were classified as primary unexplained infertility or had no previous pregnancies for at least one year after marriage, meanwhile the other 31 were classified as secondary unexplained infertility or had conceived previously, although the pregnancy may not have been successful. As much as 33 healthy women (fertile, had history of at least one childbirth) were considered as control group. The general characteristics of all subjects participated in the present study were presented in Table 1 .

Table 2 showed that a non-significant changes $(p>0.05)$ were seen in the level of BMI, leptin, TSH, FSH, $\mathrm{LH}$ and LH/FSH ratio in subjects of unexplained infertility, with compared to the healthy control. On the other hand, levels of serum 4-HNE, LOOH and $\mathrm{Cu}$ were significantly $(p<0.01)$ increased and level of GSH, SOD, CAT, TAC, Se, Zn and Mg were significantly $(p<0.01)$ decreased in subjects of unexplained infertility, compared to the healthy control.

The data obtained in Table 3, showed a non-significant changes $(p>0.05)$ in BMI level in primary and secondary unexplained infertility subjects $(22.4 \pm 3.5$ and $22.3 \pm 2.6$ $\left.\mathrm{kg} / \mathrm{m}^{2}\right)$, compared with that of control $\left(21.7 \pm 1.4 \mathrm{~kg} / \mathrm{m}^{2}\right)$, respectively. The data also showed that there were a nonsignificant differences $(p>0.05)$ in levels of FSH, LH, PRL

Table 1. The demographic characteristics of present study (n=96).

\begin{tabular}{|c|c|c|c|}
\hline \multirow[b]{2}{*}{ The Characteristics } & \multirow[b]{2}{*}{ Control } & \multicolumn{2}{|c|}{ Unexplained Infertility (UI) } \\
\hline & & $\begin{array}{c}\text { Primary } \\
\left(1^{\circ} \mathrm{UI}\right)\end{array}$ & $\begin{array}{c}\text { Secondary } \\
\left(2^{\circ} \mathrm{UI}\right)\end{array}$ \\
\hline Total (n) & 33 & 32 & 31 \\
\hline Age $($ mean \pm SD) & $30.92 \pm 5.90$ & $28.36 \pm 6.64$ & $30.72 \pm 6.12$ \\
\hline BMI $\left(\mathrm{kg} / \mathrm{m}^{2}\right)$ & $21.7 \pm 1.4$ & $22.45 \pm 3.5$ & $22.31 \pm 2.6$ \\
\hline \multicolumn{4}{|l|}{ Smoking habit } \\
\hline Negative & 24 & 25 & 23 \\
\hline Positive & 9 & 7 & 8 \\
\hline \multicolumn{4}{|l|}{ Demographic area } \\
\hline Urban & 28 & 29 & 30 \\
\hline Rural & 5 & 3 & 1 \\
\hline \multicolumn{4}{|l|}{ Education } \\
\hline Learned & 30 & 31 & 29 \\
\hline Illiterate & 3 & 1 & 2 \\
\hline \multicolumn{4}{|l|}{ Employment } \\
\hline Employed & 32 & 32 & 30 \\
\hline Not employed & 1 & 0 & 1 \\
\hline
\end{tabular}


Table 2. The levels of total parameters measured in the present study.

\begin{tabular}{|c|c|c|c|c|c|c|c|}
\hline \multirow{3}{*}{ Parameters } & \multicolumn{5}{|c|}{$\begin{array}{l}\text { Unexplained Infertility (UI) } \\
\qquad(n=63)\end{array}$} & \multirow{3}{*}{$\begin{array}{c}\begin{array}{c}\text { Control } \\
(n=33)\end{array} \\
\text { Mean } \pm \text { SD }\end{array}$} & \multirow{3}{*}{$p$-value } \\
\hline & \multirow{2}{*}{ Mean \pm SD } & \multirow{2}{*}{ SE } & \multirow{2}{*}{ Range } & \multicolumn{2}{|c|}{ 95\% C.I } & & \\
\hline & & & & Lower & Upper & & \\
\hline BMI $\left(\mathrm{kg} / \mathrm{m}^{2}\right)$ & $22.3 \pm 3.0$ & 0.67 & $17.9-26.9$ & 20.9 & 23.8 & $21.7 \pm 1.4$ & $p>0.05$ \\
\hline $\mathrm{FSH}(\mu \mathrm{U} / \mathrm{mL})$ & $5.4 \pm 1.0$ & 0.23 & $4.5-8.6$ & 4.9 & 5.9 & $5.3 \pm 0.8$ & $p>0.05$ \\
\hline PRL (ng/mL) & $14.9 \pm 1.6$ & 0.37 & $11.1-18.2$ & 14.1 & 15.7 & $15.0 \pm 1.7$ & $p>0.05$ \\
\hline $\mathrm{TSH}(\mu \mathrm{U} / \mathrm{mL})$ & $2.2 \pm 0.3$ & 0.06 & $1.8-2.9$ & 2.1 & 2.3 & $2.4 \pm 0.6$ & $p>0.05$ \\
\hline $\mathrm{LH}(\mu \mathrm{U} / \mathrm{mL})$ & $3.3 \pm 0.9$ & 0.21 & $1.9-6.1$ & 2.8 & 3.7 & $3.4 \pm 0.8$ & $p>0.05$ \\
\hline Leptin (ng/mL) & $28.4 \pm 1.3$ & 0.3 & $25.9-30.3$ & 27.7 & 29.0 & $27.2 \pm 2.3$ & $p>0.05$ \\
\hline LOOH (nmol/mL) & $7.8 \pm 1.3$ & 0.31 & $2.5-9.0$ & 7.2 & 8.5 & $3.4 \pm 1.0$ & $p<0.01$ \\
\hline 4-HNE (ng/mL) & $12.2 \pm 1.2$ & 0.28 & $10.1-15.0$ & 11.6 & 12.8 & $8.4 \pm 0.4$ & $p<0.01$ \\
\hline SOD (U/mL) & $9.8 \pm 1.2$ & 0.27 & $8.0-11.4$ & 9.2 & 10.4 & $17.6 \pm 1.3$ & $p<0.01$ \\
\hline CAT (U/mL) & $15.1 \pm 0.8$ & 0.18 & $13.4-16.1$ & 14.7 & 15.5 & $25.1 \pm 1.1$ & $p<0.01$ \\
\hline TAC (mmol/L) & $1.4 \pm 0.5$ & 0.11 & $0.6-2.7$ & 1.1 & 1.6 & $2.5 \pm 0.3$ & $p<0.01$ \\
\hline $\mathrm{GSH}(\mu \mathrm{mol} / \mathrm{L})$ & $53.8 \pm 2.9$ & 0.65 & $50.0-59.9$ & 52.4 & 55.2 & $72.7 \pm 5.1$ & $p<0.01$ \\
\hline $\mathrm{Se}(\mathrm{ng} / \mathrm{mL})$ & $72.9 \pm 4.7$ & 1.06 & $62.0-79.0$ & 69.7 & 74.2 & $89.9 \pm 5.4$ & $p<0.01$ \\
\hline $\mathrm{Cu}(\mu \mathrm{g} / \mathrm{mL})$ & $0.28 \pm 0.12$ & 0.02 & $0.02-0.54$ & 0.22 & 0.34 & $0.10 \pm 0.08$ & $p<0.01$ \\
\hline $\mathrm{Zn}(\mu \mathrm{g} / \mathrm{mL})$ & $0.72 \pm 0.02$ & 0.01 & $0.67-0.76$ & 0.71 & 0.73 & $1.04 \pm 0.04$ & $p<0.01$ \\
\hline $\operatorname{Mg}(\mu \mathrm{g} / \mathrm{mL})$ & $18.30 \pm 0.14$ & 0.03 & $18.10-18.50$ & 18.20 & 18.30 & $22.60 \pm 0.10$ & $p<0.01$ \\
\hline
\end{tabular}

Data are presented as mean \pm standard deviation (SD); SE: standard errors; $\mathrm{n}$ : number of the subjects; range: difference between the highest and lowest values in the set; 95\% CI: confidence interval/limits (lower and upper). $p>0.05: p$-value not significant, $p<0.05$ : $p$-value significant; $p<0.01: p$-value highly significant, indicating the level of significance in comparison with the corresponding control value.

and TSH were seen in primary and secondary subjects $(5.0 \pm 0.6 ; 5.0 \pm 0.6 \mu \mathrm{U} / \mathrm{mL}),(3.2 \pm 0.8 ; 3.4 \pm 0.6 \mu \mathrm{U} / \mathrm{mL})$, $(14.7 \pm 1.6 ; 14.71 .5 \mathrm{ng} / \mathrm{mL})$, and $(2.3 \pm 0.4 ; 2.3 \pm 0.4 \mu \mathrm{U} / \mathrm{mL})$ with compared to control $(5.0 \pm 0.8 \mu \mathrm{U} / \mathrm{mL}),(3.4 \pm 0.8 \mu \mathrm{U} /$ $\mathrm{mL}),(15.0 \pm 1.7 \mathrm{ng} / \mathrm{mL}),(2.4 \pm 0.6 \mu \mathrm{U} / \mathrm{mL})$, respectively. The level of serum leptin showed no significant difference ( $p>$ 0.05 ) in women with primary and secondary unexplained infertility $(28.71 \pm 1.10$ and $28.10 \pm 1.56 \mathrm{ng} / \mathrm{mL})$ as compared to the control group $(27.16 \pm 2.45 \mathrm{ng} / \mathrm{mL})$, respectively.

Furthermore, the results showed a highly significantly $(p<0.01)$ increases in levels of serum LOOH $(7.7 \pm 2.1$; $8.2 \pm 0.4 \mathrm{nmol} / \mathrm{mL}), 4-\mathrm{HNE}(12.1 \pm 0.7 ; 12.3 \pm 1.6 \mathrm{ng} / \mathrm{mL})$ and $\mathrm{Cu}(0.23 \pm 0.12 ; 0.34 \pm 0.10 \mu \mathrm{g} / \mathrm{mL})$ in subjects of primary and secondary unexplained infertility compared to control $(3.4 \pm 1.0 \mathrm{nmol} / \mathrm{mL}),(8.4 \pm 0.47 \mathrm{ng} / \mathrm{mL})$ and $(0.10 \pm 0.08 \mu \mathrm{g} /$ $\mathrm{mL}$ ), respectively (Table 4 , Table 5 ). On the other hand, levels of serum SOD, CAT, TAC and GSH were significantly $(p<0.01)$ decreased in subjects of primary and secondary unexplained infertility $(10.1 \pm 1.0 ; \quad 12.4 \pm 1.4 \quad \mathrm{U} / \mathrm{mL})$, $(15.0 \pm 0.9 ; 15.2 \pm 0.7 \mathrm{U} / \mathrm{mL}),(1.5 \pm 0.7 ; 1.3 \pm 0.1 \mathrm{mmol} / \mathrm{L})$ and $(53.3 \pm 2.5 ; 54.3 \pm 3.3 \mu \mathrm{mol} / \mathrm{L})$ compared to the control $(17.6 \pm 1.3 \mathrm{U} / \mathrm{mL}),(25.1 \pm 1.1 \mathrm{U} / \mathrm{mL}),(2.5 \pm 0.3 \mathrm{mmol} / \mathrm{L})$ and $(2.5 \pm 0.3 \mu \mathrm{mol} / \mathrm{L})$, respectively.

Moreover, this study showed that a significant decreases $(p<0.01)$ was seen in blood levels of Se, $\mathrm{Zn}$, and $\mathrm{Mg}$ in subjects of primary and secondary unexplained infertility $\quad(70.1 \pm 4.2 ; \quad 73.9 \pm 4.7 \quad \mathrm{ng} / \mathrm{mL}), \quad(0.71 \pm 0.03$; $0.70 \pm 0.11 \mu \mathrm{g} / \mathrm{mL})$ and $(18.10 \pm 0.06 ; 18.40 \pm 0.05 \mu \mathrm{g} / \mathrm{mL})$ compared to control $(89.9 \pm 5.4 \mathrm{ng} / \mathrm{mL}, 1.04 \pm 0.04 \mu \mathrm{g} / \mathrm{mL}$ and $22.60 \pm 0.10 \mu \mathrm{g} / \mathrm{mL}$ ), respectively. A highly significant $(p<0.01)$ increases was found in the levels of serum $\mathrm{Cu}$ $(0.23 \pm 0.12 ; 0.34 \pm 0.10 \mu \mathrm{g} / \mathrm{mL})$ in subjects of primary and secondary unexplained infertility compared to control $(0.10 \pm 0.08 \mu \mathrm{g} / \mathrm{mL})$, respectively (Table 5 ). 
Table 3. Levels of BMI, leptin and some hormones in women of healthy control and unexplained infertility. The values are the mean $\pm \mathrm{SD}$.

\begin{tabular}{|c|c|c|c|c|}
\hline \multirow{2}{*}{ Parameters } & \multicolumn{2}{|c|}{$\begin{array}{l}\text { Unexplained Infertility (UI) } \\
\qquad(n=63)\end{array}$} & \multirow{2}{*}{$\begin{array}{c}\text { Control } \\
(n=33)\end{array}$} & \multirow{2}{*}{$p$-value } \\
\hline & $\begin{array}{c}\text { Primary }\left(1^{\circ} \mathrm{UI}\right) \\
(\mathrm{n}=\mathbf{3 2})\end{array}$ & $\begin{array}{c}\text { Secondary }\left(2^{\circ} \mathrm{UI}\right) \\
(\mathrm{n}=\mathbf{3 1})\end{array}$ & & \\
\hline BMI $\left(\mathrm{kg} / \mathrm{m}^{2}\right)$ & $22.4 \pm 3.5$ & $22.3 \pm 2.6$ & $21.7 \pm 1.4$ & $p>0.05$ \\
\hline $\mathrm{FSH}(\mu \mathrm{U} / \mathrm{mL})$ & $5.0 \pm 0.6$ & $5.0 \pm 0.6$ & $5.0 \pm 0.8$ & $p>0.05$ \\
\hline PRL (ng/mL) & $14.7 \pm 1.6$ & $14.7 \pm 1.5$ & $15.0 \pm 1.7$ & $p>0.05$ \\
\hline $\mathrm{TSH}(\mu \mathrm{U} / \mathrm{mL})$ & $2.3 \pm 0.4$ & $2.3 \pm 0.4$ & $2.4 \pm 0.6$ & $p>0.05$ \\
\hline $\mathrm{LH}(\mu \mathrm{U} / \mathrm{mL})$ & $3.2 \pm 0.8$ & $3.4 \pm 0.6$ & $3.4 \pm 0.8$ & $p>0.05$ \\
\hline Leptin (ng/mL) & $28.7 \pm 1.1$ & $28.1 \pm 1.6$ & $27.2 \pm 2.4$ & $p>0.05$ \\
\hline
\end{tabular}

\section{Discussion}

The true definition of infertility is the failure to achieve a successful pregnancy after 12 months or more of unprotected intercourse and the infertility evaluation is initiated after 1 year of trying to conceive. Unexplained infertility is a term that may give a characterization to an infertile couple which has normal standard investigations such as semen analysis, tubal patency, and laboratory assessment of ovulation. (14) To the best of our knowledge, this is the first study on the comparison of the level of leptin, oxidant/antioxidant status and some trace elements in women of healthy control and unexplained infertility in Basrah province (southern of Iraq). In the present study, data showed that more than half of the unexplained patients were non smokers. Also, most of the volunteers from both patients' women with unexplained infertility and healthy control were from urban, all of them received a well-learned and also they had a good employed place. Therefore, our results cannot represents the actual state of the entire patients group in Iraq due to the low number of patients and also depends on the cooperatively of patients and their willing to participate in the present study.

The major differences between urban and rural areas are the differences in pollution, environments, social, psychological, genetic, food factors and others, which are increasing dramatically in urban areas. On the other hand, the psychological of women may be affected by work pressures and its requirements and household factors such as childs-rearing and marital relationships that are often tense and not good which are increased the imbalance of oxidant/antioxidant.(15)

Levels of leptin hormone may be change during the menstrual cycle. In a recent study, researchers have shown increased the levels of serum leptin in certain phases of

Table 4. Levels of enzymatic and non-enzymatic antioxidants in women of healthy control and unexplained infertility. The values are the mean $\pm \mathrm{SD}$.

\begin{tabular}{|c|c|c|c|c|}
\hline \multirow{2}{*}{ Parameters } & \multicolumn{2}{|c|}{$\begin{array}{l}\text { Unexplained Infertility (UI) } \\
\qquad(\mathrm{n}=63)\end{array}$} & \multirow{2}{*}{$\begin{array}{c}\text { Control } \\
(\mathrm{n}=33)\end{array}$} & \multirow{2}{*}{$p$-value } \\
\hline & $\begin{array}{c}\text { Primary }\left(1^{\circ} \mathrm{UI}\right) \\
(\mathrm{n}=32)\end{array}$ & $\begin{array}{c}\text { Secondary }\left(2^{\circ} \mathrm{UI}\right) \\
(\mathrm{n}=31)\end{array}$ & & \\
\hline $\mathrm{LOOH}(\mathrm{nmol} / \mathrm{mL})$ & $7.7 \pm 2.1$ & $8.2 \pm 0.4$ & $3.4 \pm 1.0$ & $p<0.01$ \\
\hline 4-HNE (ng/mL) & $12.1 \pm 0.7$ & $12.3 \pm 1.6$ & $8.4 \pm 0.5$ & $p<0.01$ \\
\hline $\mathrm{SOD}(\mathrm{U} / \mathrm{mL})$ & $10.1 \pm 1.0$ & $12.4 \pm 1.4$ & $17.6 \pm 1.3$ & $p<0.01$ \\
\hline CAT (U/mL) & $15.0 \pm 0.9$ & $15.2 \pm 0.7$ & $25.1 \pm 1.1$ & $p<0.01$ \\
\hline TAC (mmol/L) & $1.5 \pm 0.7$ & $1.3 \pm 0.1$ & $2.5 \pm 0.3$ & $p<0.01$ \\
\hline $\mathrm{GSH}(\mu \mathrm{mol} / \mathrm{L})$ & $53.3 \pm 2.5$ & $54.3 \pm 3.3$ & $72.7 \pm 5.3$ & $p<0.01$ \\
\hline
\end{tabular}


Table 5. Levels of essential trace elemensts in women of healthy control and unexplained infertility. The values are the mean $\pm \mathrm{SD}$.

\begin{tabular}{|c|c|c|c|c|}
\hline \multirow{2}{*}{ Parameters } & \multicolumn{2}{|c|}{$\begin{array}{l}\text { Unexplained Infertility (UI) } \\
\qquad(\mathrm{n}=63)\end{array}$} & \multirow{2}{*}{$\begin{array}{l}\text { Control } \\
(n=33)\end{array}$} & \multirow{2}{*}{$p$-value } \\
\hline & $\begin{array}{c}\text { Primary }\left(1^{\circ} \mathrm{UI}\right) \\
(\mathrm{n}=32)\end{array}$ & $\begin{array}{c}\text { Secondary }\left(2^{\circ} \mathrm{UI}\right) \\
(\mathrm{n}=31)\end{array}$ & & \\
\hline $\mathrm{Se}(\mathrm{ng} / \mathrm{mL})$ & $70.1 \pm 4.2$ & $73.9 \pm 4.7$ & $89.9 \pm 5.4$ & $p<0.01$ \\
\hline $\mathrm{Cu}(\mu \mathrm{g} / \mathrm{mL})$ & $0.23 \pm 0.12$ & $0.34 \pm 0.10$ & $0.10 \pm 0.08$ & $p<0.01$ \\
\hline $\mathrm{Zn}(\mu \mathrm{g} / \mathrm{mL})$ & $0.71 \pm 0.03$ & $0.70 \pm 0.11$ & $1.04 \pm 0.04$ & $p<0.01$ \\
\hline $\operatorname{Mg}(\mu \mathrm{g} / \mathrm{mL})$ & $18.10 \pm 0.06$ & $18.40 \pm 0.05$ & $22.60 \pm 0.10$ & $p<0.01$ \\
\hline
\end{tabular}

menstrual cycle in women, and significant correlations between leptin and PRL were found in the follicular phase and also with free testosterone in males. Hence, it may be considered a reliable scientific proof that from the first to fifth days of the cycle leptin levels are more stable with compared to those produced later in the cycle.(16) In the present study, the tests of leptin levels have been done on the two or third day of the menstruation cycle for precise cycle-independent measurements. Leptin is one of the new biomarker in the problem of energy balance, Gonadotropinreleasing hormone $(\mathrm{GnRh})$ release, LH and FSH release, weight control, ovarian function and infertility.(17)

The relationship between leptin and infertility has been reported in several studies; but, with unexplained infertility a few studies have examined this relationship as follow: A scientific study conducted in 1997 reported that levels of serum leptin have a direct correlation with BMI and body fat percentage during different phases of the menstrual cycle and pregnancy. Furthermore, although leptin levels are not very different in their cerebrospinal fluid, it was found increasing in the obese women than in the underweight women.(18) In 2000, it was reported that the leptin levels in ovary dysfunction are associated with the BMI and also do not appear to be directly involved in the regulation of ovarian function.(18) In accordance to previous studies in 2001 and 2005 that the similarity of BMI in the infertile patients which belong to three different groups, the unexplained infertility, the endometriosis and the polycystic ovary may be was noted as the main reason for their lack of changes in leptin levels.(19)

In 2007, a study was carry out to compare the levels of leptin between the women with unexplained infertility and the group of fertile women. It was concluded that there was a significantly increased in level of leptin in group of women with unexplained infertility compared to fertile women group.(20) Another study conducted in 2008, clearly showed that the significantly elevated of leptin levels in obese women have an ability to inhibit the growth of immature follicles and prevent oocyte maturation, and it may be leads to infertility.(21) Increased leptin in obese women may significantly correlation with the menstrual dysfunction, decreased fertility, increased risk of miscarriage and obstetric and neonatal complications. Furthermore, higher BMI in men is may significantly correlated with abnormal semen parameters and results in adverse effects on fertility; thus, couples trying to conceive must recommended to get to a BMI of $20-25 \mathrm{~kg} / \mathrm{m}^{2}$.(8)

Moreover, a negative significant correlation was seen between leptin and exercise in control group and patients with the history of regular exercise. Studies proven that only 2 months of aerobic exercise during the follicular phase of menstruation significantly decreases plasma leptin in obese women (22). In 2016, it was reported that level of serum leptin is closely associated with BMI and physical activity in the normal group and there were no statistically significant differences between the levels of serum leptin in women with unexplained infertility and healthy fertile women group.(18) In this work, no significant changes have been shown in serum leptin level between unexplained infertility subjects and control.

The following reasons may give an possible explanation for these observations in levels of leptin hormone; first, is that the BMI was similar and within normal range in all groups of women with unexplained infertility (primary and secondary) and healthy control group. In accordance to previous experimental studies that the number of fat cells and their size are possible determinants of leptin production rates since it is mainly secreted by adiposities; thus the obesity have a positive significantly correlation with secretion of leptin hormone and this strong relationship exists between BMI and serum leptin may increase in the obese group than non-obese.(23) 
Second, are the non-significant differences between serum levels of the hormones FSH, LH and LH/FSH ratio, PRL and TSH in primary and secondary type of unexplained infertility and the healthy fertile group. Experimental studies have proved that increased level of leptin lead to the significant changes in levels of hormones FSH, LH and LH/ FSH ratio, PRL and TSH in infertility group as compared to control.(24) Also, there are number of problems resulting from aberrant dysfunction of hypothalamic-pituitaryovarian axis which lead to hormonal disorders in the female reproductive system and caused infertility. Thyroid disease is a well certainly known cause for irregularity of menstrual cycle in women and infertility. It may be due to its affects on many organs including male and female gonads, which interferes with reproductive physiology in human. Besides that, it may also lead to significantly reduces in the likelihood of pregnancy and adversely affects on pregnancy outcome, as well as become relevant in the algorithm of reproductive dysfunction.(25) Difficulty in conceive or fertility may be a major psychological burden. The real assessment of these disorders includes a multidimensional diagnostic approach, with a pivotal contribution from clinical laboratories.(26) Thyroid disorders interfere with many aspects of reproduction and pregnancy. The prolactin and thyroid hormones, especially TSH hormone which is secreted from anterior lope in pituitory gland, is an important component of infertility in women, and their levels have closely association with BMI level.(27) In the present study we excluded the volunteer's women with any endocrinology diseases such as thyroid dysfunction and diabetes mellitus, because it affects the levels of hormones, especially TSH and PRL and causes menstrual irregularity.

Furthermore, swings in the level of hormones may be lead to increase the level of free radicals and the imbalance of the case of oxidants/antioxidants and this increases the probability of infertility. Hormonal imbalance is also a clear cause of a condition that can be diagnosed and treated which cannot be classified as unexplained infertility. On the other hand, there are many reports that LH/FSH ratio can be used as biomarker of pregnancy outcome in infertile women (28), but this was not confirmed in the present work. our data, revealed that no differences in TSH and PRL levels between women in the studied groups, which may give an indication that these hormones are not useful in diagnosis and prediction of live birth in women with unexplained infertility. Previous study in 2003 indicated that women with male unexplained infertility had relatively elevated level of TSH and lower levels of PRL hormone. In another different study in the year 2000 the results indicated that levels of TSH hormone were increased significantly in women with unexplained infertility, while the significantly decreased levels of TSH hormone were seen in women with male infertility, and ovulatory dysfunction. On the other hand, the irregular and disorders in menstrual cycle of women suffered from hypothyroidism are rarer than previously reported.(28)

Increased generation of ROS and/or reactive nitrogen species (RNS) as well as the non radical species derived from free radicals can lead to increased oxidative stress, thus result in imbalance in the intracellular redox homeostasis. So, increased oxidative stress lead to decreased in total antioxidants, thus result in can precipitate pathologies in the female reproductive tract and this may be due to any excess levels of reactive radical and non-radical species generated are intercepted by antioxidants. The reactive oxygen species have physiologic functions and act as mediators in various signaling processes, and pathologic roles on the female reproductive tract.

Moreover, the pathological role is exerted by various mechanisms including the lipid damage, inhibition of proteogenesis and increased depletion of ATP. Therefore, many studies have examined how free radicals or ROS are effects on a gamut of physiologic functions in female reproduction such as are oocyte maturation, ovarian steroid synthesis, ovulation, and implantation, formation of fluid filled cavity, blastocyst, luteolysis and luteal maintenance in pregnancy.(29) On the other hand, other studies have reported that oxidative stress is may almost involved in all various diseases in women such as abortions, preeclampsia, hydatidiform mole, fetal teratogenecity, preterm labor and intrauterine growth retardation. Thus, the imbalance in oxidant/antioxidant ration may lead to an immense burden for maternal and fetal, morbidity and mortality, which suggests that oxidative stress, plays a role in the proinflammatory changes seen with polycystic ovary syndrome (PCOS) and also in the pathogenesis of endometriosis and tubal factor infertility.(30) The increase in the level of free radicals lead to oxidative stress that show a range of pathological changes that affect the reproductive functions in both men and women, and this relationship has been investigated in several studies as follow: The increase in the level of free radicals lead to oxidative stress that show a range of pathological changes that affect the reproductive functions in both men and women, and this relationship has been investigated in several studies as follow: NADPH molecule has a main role in oxidative stress that mediated DNA damage in abnormal sperm morphology.(31) Also, the 
ROS have a harmful role in unexplained infertility and in infertility that caused by endometriosis.(32)

MDA level was significantly increased in peritoneal fluid of patients with unexplained infertility and endometriosis compared to that in controls which is in accordance with our results. Moreover, there are a highly significantly levels of nitric oxide in peritoneal fluid of patients with unexplained infertility and with infertility that caused by endometriosis.(31) SOD and CAT, primary defenses against oxidative stress, are found to be significantly lowered in endometrial in cases of infertility than in controls. Also, level of CAT is found highly significantly in women with secondary infertility within compared to in primary infertility.(31) Furthermore, some scientific studies have shown significantly decreased level of peritoneal total antioxidant status (TAS) compared to those in plasma TAS.(31)

In this study, we studied the levels of 4-HNE and LOOH (marker of oxidative stress), and GSH, SOD, CAT, TAC (enzymatic and non-enzymatic antioxidant) in blood serum and our data were clearly showed that levels of serum 4-HNE, $\mathrm{LOOH}$ and $\mathrm{Cu}$ were significantly increased and level of GSH, SOD, CAT, TAC were significantly decreased in primary and secondary type of unexplained infertility, with compared to control. Oxidative stress exerts a hazard effect on female fertility potential in a number of ways, for example it may affect ovulation, fertilization, implantation and embryo development. This may explain the mechanism of ROS that appears in both physiological and pathological role in the female reproductive tract.(4) On the other hand, it is thought that the cooperation of all antioxidants systems in human blood can provides a greater protection against attacks by ROS than any antioxidant alone. Thus, the TAC can be defined as a dynamic equilibrium that is influenced by the interactions of each blood anti-oxidative constituents.(33)

In our study, the results indicated that a significant decrease was seen in serum $\mathrm{Zn}$ level in primary and secondary type of unexplained infertility subjects compared with that of control. Same table reflect the levels of serum $\mathrm{Cu}$ with their significant increases in primary and secondary type of unexplained infertility subjects compared with that of control. Some studies clearly reported that deficiency of $\mathrm{Zn}$ may be interfere with fertility by disrupting menstrual cycle, because it very impairment in the synthesis and secretion of two important hormones FSH and LH. Therefore, oral supplementation of $\mathrm{Zn}$ has been found to correct such impairment.(34) Also, it has been reported that $\mathrm{Zn}$ plays a vital role in differentiation sex, in spermatogenesis, as a first direct evidence for the important role of this metal in growth and development. Furthermore, other studies reported that decreased levels of serum $\mathrm{Zn}$ were observed in women suffering from premenstrual tension syndrome with compared to the healthy control group.(35) This may be give clearly indication that the imbalance in level of serum copper could be the major cause of in primary and secondary type of unexplained infertility. A possible explanation for the interference between the significantly higher level of serum copper and infertility might be due to the following reasons; first, excessive amounts of Cumay interfere with neuronal signaling in central nerve system which are good responsible for the neuroendocrine regulation of fertility. Second, the excessive in serum $\mathrm{Cu}$ out weights the role of $\mathrm{Zn}$ very necessary for regulation of ovulation process. Therefore, significantly higher level of serum $\mathrm{Cu}$ levels in pregnant may be cause an adversely affected on fetal brain growth and subtle birth defects may occur.(36)

In the present study, level Se was found to be significantly decreased in unexplained infertility patients when compared to healthy control group. It has a vital role may because it is the main element constituent of the active site of the enzyme glutathione peroxidase (GPx). GPx is an active enzyme against oxidative stress results from ROS, thus it is able to reduce formation of free radicals and protects cellular membranes against the adverse effects of lipid peroxides. The significantly decreased levels of selenium in blood may be results from expose the patients women to an increased oxidative stress which is known to be correlated with the pathogenesis of all known diseases. (13) Also, decreased level of this element in blood might be gave an indication of increased the production of free radical and highly scavenging activity of either selenium or glutathione peroxidase enzyme. Furthermore, scientific surveys have demonstrated that Se element has a significant vital role in the women especially in maintained of the undisturbed functioning of the reproductive system. Thus, many studies have reported the significant correlations between the Se intake and fertility as well as disorders of procreation processes.(37) In women, the significantly decline in levels of blood Se element may lead to the long-term complications of gestational, miscarriages and the damaging of the nervous as well as failure of immune systems of the fetus. Hence, low birth weight of a newborn, may represent a predictor of the significantly reduced levels of blood Se in the early stage of women pregnancy. On the same state, the infertility in men may gate from significantly decreased of Se elements which lead to deterioration in the quality of semen and in sperm motility. For this reason, 
dietary supplementation is very necessary and is of utmost significance for both women and men in the case of selenium deficiencies especially in the procreation period.(37)

Another important trace element is $\mathrm{Mg}$ which is ingested with food or water, and has a vital role in the maintenance of the structure of ribosomes, nucleic acids and some proteins, needed to stay healthy as is an essential cofactor for multiple enzymes involved in glucose metabolism. It has been postulated that this trace element may has an ability to play a two major and vital roles in biological systems, as follow $\mathrm{Mg}$ may show an compete state with calcium on the binding sites of proteins and cell membranes, and $\mathrm{Mg}$ also has an ability to form chelates with any important intracellular anionic ligands especially the energy molecule, ATP.(38)

Decreased levels of trace elements such as $\mathrm{Zn}, \mathrm{Se}$ and $\mathrm{Mg}$ have been shown in various reproductive events like infertility, spontaneous abortions, congenital anomalies, preeclampsia, placental abruption, premature rupture of membranes, still births and low birth weight.(39) Lower level of $\mathrm{Mg}$ can paradoxically increase the risk factor of, or protect against oncogenesis. In the cycle of cells, the $\mathrm{Mg}$ element has been reported that it may has a vital and central role in the cell, thus its deficiency is an important conditioner in precancerous cell transformation. On the other hand, at higher levels, $\mathrm{Mg}$ can cause damage to the brain, liver, kidneys, and the developing foetus.(40)

\section{Conclusion}

Understanding the relationship of serum leptin and unexplained infertility as well as the vital role of leptin in the physiology and pathophysiology of the women reproductive process may be requires further work on patients women with unexplained infertility in Basrah province, such as study the leptin level in patients women who have a higher BMI and its correlation with other predisposing factors. There is an involvement of oxidants/antioxidants status in infertility and thus may have potential application in diagnosis and treatment of female infertility. The results of this study may give an indication about the involvement of essential trace elements such as $\mathrm{Se}, \mathrm{Zn}$ and Mg deficiency and/or copper overload as an important etiological role in the pathogenicity of unexplained infertility and therapeutic intervention with these trace elements as supplement in a suitable formula may be beneficial and might give a promise in this respect.

\section{Acknowledgements}

The authors thank all the staff of infertility center at Basra hospital for Obstetrics and children in Basrah GovernorateIraq, especially the consultant professor Dr. Abdul-kareem Hussain Sabar and assistant professor Dr. Nateek Dicran Caspar. The authors are also highly thankful to the head of Chemistry Department, College of Science, University of Basrah for providing their kind support and facilities to accomplish the present research project within time.

\section{References}

1. Somigliana E, Paffoni A, Busnelli A, Filippi F, Pagliardini L, Vigano $\mathrm{P}$, et al. Age-related infertility and unexplained infertility: an intricate clinical dilemma. Hum Reprod. 2016; 31: 1390-6.

2. Sadeghi MR. Unexplained infertility, the controversial matter in management of infertile couples. J Reprod Infertil. 2015; 16: 1-2.

3. Al-Fartosy AJM, Mohammed IM. Study the biochemical correlation of insulin resistance with $\mathrm{HbAlc}$ and sex hormones in NIDDM patients/Meisan-Iraq. J Diab Mel. 2017; 7: 302-15.

4. Rajeshwary P, Nagaprasanth M, Mahaboob SR, Obulesu G. Evaluation of oxidative stress markers in infertile women. Int Arch Integr Med. 2016; 3: 239-44.

5. Agarwal A, Aponte-Mellado A, Premkumar BJ, Shaman A, Gupta S. The effects of oxidative stress on female reproduction: a review. Reprod Biol Endocrinol. 2012; 10: 49.

6. Broughton DE, Moley KH. Obesity and female infertility: potential mediators of obesity's impact. Fertil Steril. 2017; 107: 840-7.

7. Tong $\mathrm{Q}$, Yong $\mathrm{Xu}$. Central leptin regulation of obesity and fertility. Curr Obes Rep. 2012; 1: 236-44.

8. Faramarzi M, Salmalian H. Association of psychologic and nonpsychologic factors with primary dysmenorrhea. Iran Red Crescent Med J. 2014; 16: 1-9. doi: 10.5812/ircmj.16307.

9. Saruhan BG, Erdoğan S, Topaloğlu U, Akbalık ME, Bayram B, Ketani MA, et al. Expression and biological activity of ghrelin, obestatin, and leptin in deferent ducts of the bull and RAM. Slov Vet Res. 2018; 55: 151-9.

10. Kamyabi Z, Gholamalizade T. A comparative study of serum and follicular fluid leptin concentrations among explained infertile, unexplained infertile and fertile women. Int J Fertil Steril. 2015; 9: $150-6$.

11. Infertility Workup for The Women's Health Specialist. ACOG committee opinion no. 781. American College of Obstetricians and Gynecologists. Obstet Gynecol. 2019; 133: e377-84.

12. Al-Fartosy AJM, Shanan SK, Awad NA. Biochemical study of the effects of some heavy metals on oxidant/antioxidant status in gasoline station workers/Basra-Iraq. Int J Sci Res Public. 2017; 7: 83-94.

13. Al-Fartosy AJM, Awad NA, Abdalemam DJ. Biochemical study of the effect of insulin resistance on adiponectin, lipid profile and some antioxidants elements with relation to obesity in type 2 diabetic patients/Basrah-Iraq. Amer J Biochem. 2017; 7: 73-82.

14. Ekka CD, Jain A, Puri M. Role of hormones in unexplained infertility. Indian J Med biochem. 2016; 20: 34-7. 
15. Callahan T, Caughey AB. Puberty, the menstrual cycle, and the menopause. Infertility and assisted reproductive technologies. In: Blueprints Obstetrics and Gynecology. 7th edition. Philadelphia: Wolters Kluwer Health; 2018. p.212-22.

16. Kumari P, Jaiswar SP, Shankhwar P, Deo S, Ahmad K, Iqbal B, et al. Leptin as a predictive marker in unexplained infertility in north indian population. J Clin Diagn Res. 2017; 11: 28-31.

17. Ajala OM, Ogunro PS, Elusanmi GF, Ogunyemi OE, Bolarnide AA. Changes in serum leptin during phases of menstrual cycle of fertile women: relationship to age groups and fertility. Int J Endocrinol Metab. 2013; 11: 27-33.

18. Tafvizi F, Masomi M. Comparison of serum leptin level in women with unexplained infertility and fertile women in Iran. J Obstet Gynecol India. 2016; 66: 466-70.

19. Rehman KA, Awan FR. Leptin resistance: a possible interface between obesity and pulmonary-related disorders. Int J Endocrinol Metab. 2016; 14: 1-6. doi: 10.5812/ijem.32586.

20. Farooq R, Lutfullah S, Ahmed M. Serum leptin levels in obese infertile men and women. Pak J Pharm Sci. 2014; 27: 67-71.

21. Tafvizi F, Masomi M. Association of body mass index with leptin and other hormonal parameters in women with unexplained infertility and fertile women. J Fas Univ Med Sci. 2016; 6: 44-51.

22. Irandust $\mathrm{KH}$, Rahmani Nia F, Mohebbi H. The effect of aerobic exercise on plasma ghrelin and leptin concentrations in obese and normal weight women. Olympic. 2011; 50: 87-100.

23. Fakor F, Sharami SH, Milani F, Mirblouk F, Kazemi S, Pourmarzi D, et al. The association between level of maternal serum leptin in the third trimester and the occurrence of moderate preterm labor. J Turk Ger Gynecol Assoc. 2016; 17: 182-5.

24. Jungheim S, Travieso JL, Carson KR, Moley KH. Obesity and reproductive function emily. Obstet Gynecol Clin North Am. 2012; 39: 479-93.

25. Shoaib OM, ELhashimi EH. A study of serum thyroid stimulating hormone and prolactin levels of infertile females. Inter J Sci Res. 2016; 5: 836-9.

26. Hivre MD, Bhale DV, Mahat RK, Bujurge AA. Study of serum TSH and prolactin levels in patients of female infertility. Int J Rec Tre Sci Tech. 2013; 9: 144-5.

27. Safarnavadeh T, Rastegarpanah M. Antioxidants and infertility treatment, the role of Satureja Khuzestanica: a mini-systematic review. Iran J Reprod Med. 2011; 9: 61-70.
28. Murto T, Bjuresten K, Landgren BM, Stavreus-Evers A. Predictive value of hormonal parameters for live birth in women with unexplained infertility and male infertility. Reprod Bio Endoc. 2013; 11: 61-.

29. Premkumar BJ, Aponte A, Shaman A, Agarwal A. Reactive oxygen species and female infertility. Syst Biol Fre Radic Antiox. 2014; 3: 2743-72.

30. Nunez-Calonge R, Cortés S, Gutierrez Gonzalez LM, Kireev R, Vara $\mathrm{E}$, Ortega L, et al. Oxidative stress in follicular fluid of young women with low response compared with fertile oocyte donors. Reprod Biomed Online. 2016; 32: 446-56.

31. Al-Mulla A, Fazari ABE, Elkhouly M, Moghaddam N. Role of antioxidants in female fertility. Open J Obstet Gynecol. 2018; 8: $85-91$.

32. Sansone A, Lombardo F, Lenzi A. Free radicals and reproductive health. Syst Biol Fre Radic Antios. 2014; 3: 2723-42.

33. Al-Fartosy AJM, Awad NA, Zearah SA. Assessment the effect of Zn and $\mathrm{Mg}$ supplementation on total antioxidant capacity in type 2 diabetic patients. Basrah J f Sci. 2011; 28: 94-100.

34. Arhin SK, Zhao Y, Lu XS, Chetry M, Lu JQ. Effect of micronutrient supplementation on IVF outcomes: a systematic review of the literature. Reprod Biomed Online. 2017; 35: 715-22.

35. Awrahman ZA. Screening of metals such as copper $(\mathrm{Cu})$, zinc $(\mathrm{Zn})$, nickel $(\mathrm{Ni})$ and lead $(\mathrm{Pb})$ in the human blood. Kurdistan Acad J. 2015; 11: 81-7.

36. Fallah A, Mohammad-Hasani A, Colagar AH. Zinc is an essential element for male fertility: a review of $\mathrm{Zn}$ roles in men's health, germination, sperm quality, and fertilization. J Reprod Infertil. 2018; 19: 69-81.

37. Pieczynska J, Grajeta H. The role of selenium in human conception and pregnancy. J Trace Elem Med Biol. 2015; 29: 31-8.

38. Vasudevan DM, Sreekumari S. Mineral metabolism. In: Vasudevan DM, Sreekumari S, editors. Textbook of Biochemistry for Medical Students. 7th ed. New Delhi: Jaypee Brothers Medical Publishers; 2013. p.305-6.

39. Wu J, Wu S, Xie Y, Wang Z, Wu R, Cai J, et al. Zinc protects sperm from being damaged by reactive oxygen species in assisted reproduction techniques. Reprod Biomed Online. 2015; 30: 334-9.

40. Liang H, Miao M, Chen J, Chen K, Wu B, Dai Q, et al. The association between calcium, magnesium, and ratio of calcium/magnesium in seminal plasma and sperm quality. Biol Trace Elem Res. 2016; 174: $1-7$. 